\title{
Specification Guidelines for Surface Preparation of Concrete Prior to Repair
}

\author{
Luc Courard $^{1(\bowtie)}$, Benoît Bissonnette ${ }^{2}$, and Andrzej Garbacz ${ }^{3}$ \\ 1 Building Materials, Urban and Environmental Research Unit, \\ University of Liège, Building B52, Allée de la découverte 9, \\ 4000 Liège, Belgium \\ Luc.Courard@ulg. ac.be \\ 2 Civil Engineering Department, CRIB, Laval University, \\ Québec, QC G1K 7P4, Canada \\ benoit.bissonnette@gci.ulaval.ca \\ 3 Department of Building Materials Engineering, \\ Warsaw University of Technology, Al. Armii Ludowej 16, \\ 00-637 Warsaw, Poland \\ a.garbacz@il.pw.edu.pl
}

\begin{abstract}
The repair of concrete requests specific preparation operations needed for guaranteeing compatibility between substrate and new materials as well as the development of adhesion properties. These specification guidelines contain design and construction recommendations for surface preparation of concrete for repair and overlay. The paper summarizes current knowledge, best practices and results of the research concerning the surface preparation of concrete prior to application of repair/overlay materials. The specifications are applicable to repairing damaged or deteriorated concrete structures, correcting design or construction deficiencies, or upgrading a structure for new uses, or to meet more restrictive code requirements. This is based on 10 years research activities on this topic through scientific cooperation programs between Wallonia, Quebec and Poland and support of American Concrete Institute.
\end{abstract}

Keywords: Repair $\cdot$ Concrete $\cdot$ Surface $\cdot$ Preparation $\cdot$ Recommendations

\section{Introduction}

The process of concrete preparation for repair is the process by which sound, clean, and suitably roughened surfaces are produced on concrete substrates (Courard et al. 2009). This process includes the removal of unsound and, if necessary, sound concrete and bond inhibiting foreign materials from the concrete and reinforcement surfaces, opening the concrete pore structure, reinforcement damage verification and repair, if necessary (Courard et al. 2011).

Unsound or deteriorated concrete shall be defined as: concrete affected by spalling, delamination, disintegration and concrete in areas with severe cracking where active corrosion of reinforcing steel has been detected (Courard et al. 2013). "Unsound" concrete suggests that the material is in a reduced physical condition and hence 
relatively easy to remove. Alternatively "sound" concrete in all probability may be in physically good condition and involves considerable effort for its removal. Contaminated with chlorides and/or carbonated concrete is usually physically sound concrete (Bissonnette et al. 2006).

Concrete removal usually involves unsound material. However, some sound concrete is also removed to permit for adequate repair geometry, to remove contaminated concrete, to prepare embedded reinforcement, and to permit structural modifications (ICRI 310). The effectiveness of various concrete removal techniques may differ for unsound and sound concrete and a combination of techniques may be necessary (Courard et al. 2015).

\section{Concrete Removal Preparation}

\subsection{Structural Safety}

Before starting removal of existing concrete, the effect of the removal on the structural integrity should be reviewed. In cases where removal of deteriorated concrete and/or severely corroded reinforcing steel can affect the load carrying capacity of the structure or its elements, a temporary shoring system should be provided to relieve the loads from the structure or its member being repaired. Caution needs to be exercised in order that the safety of the structure is not jeopardized by repair activities.

Details of shoring to be used shall be provided by the Contractor and shall be designed and sealed by a Professional Engineer; this does not, however, in any way relieve the Contractor of his responsibility for the safety and adequacy of the shoring system.

The limitations for concrete removal such as the depth, reduction of cross section, the amount of concrete removed from the top surface, etc. shall be subject to the restrictions described in the contract.

\subsection{Precautions Prior to Concrete Removal}

The areas where concrete is to be removed shall be examined to determine if there are electrical conduits, utility lines, or other embedments which may be damaged during removal.

If required, the Contractor shall enclose work area with a plastic barrier to confine dust and debris inside the work areas. The enclosures shall be securely constructed-and inspected by the Contractor each working day to ensure that there are no holes or tears.

The Contractor shall ensure that the level of equipment exhaust fumes (such as from air compressors or portable generators) is within acceptable limits. If the fume level cannot be kept at an acceptable level using the existing garage exhaust fans, then the Contractor shall use other equipment or relocate the equipment so that the fumes can be properly exhausted away from occupied areas.

All necessary precautions shall be taken to ensure that dust or falling debris does not constitute a hazard to personnel, equipment, the structure, its occupants and the 
general public. Effective means of clearing dust and debris away from the working area shall be continuously implemented.

The extent and depth of concrete removal required shall be measured and recorded on drawings by the Contractor and agreed with the Engineer as the work proceeds (ICRI, 2013).

\subsection{Concrete Removal Geometry}

The location, number, and extent of defects shown in the Contract are indicative only. The true location, number, and extent of defects requiring repair can only be assessed properly by close inspection and other testing during the course of concrete removal. The limits of each repair shall be marked with chalk or paint by the Contractor as a series of straight lines on the surface. The limits of each repair shall be subject to agreement by the Engineer.

Areas requiring repair shall be modified to provide for simple layouts. The layouts shall be designed to reduce boundary edge length and eliminate acute angles. Excessive or complex edge conditions are usually produced by trying to closely follow the shape of the deteriorated concrete. Such edge conditions often result in shrinkage stress concentrations and cracking.

The perimeters of repairs that involve concrete removal shall provide right angle cuts to the concrete surface by saw cutting, chipping or hydrodemolition (water jetting).

\subsection{Saw Cutting}

A saw cut along the perimeter of the area where concrete is to be removed shall be provided to reduce edge spalling and to provide a sound edge surface against which the repair material will be placed (Bissonnette et al. 2014). The saw cuts shall be made to a depth of approximately $13 \mathrm{~mm}$. Where the cover to the reinforcing steel is low, disk cutting will have to be omitted in order to avoid damage to reinforcement.

The saw cut surfaces shall be roughened prior to application of a repair material (Garbacz et al. 2005). It is best achieved by sand or grit blasting at the same time as cleaning of exposed reinforcement. Care needs to be exercised when roughening the disc-cut surfaces to avoid damage to the repair cavity edges.

The advantages of the saw cutting procedure include the following:

- the saw leaves vertical edge faces;

- the forces experienced by the pavement during chipping are isolated within the sawed boundaries;

- very little spalling of the remaining pavement occurs;

- removing the deteriorated concrete within the sawed boundaries is usually easier and faster when the boundaries are sawed than when they are not sawed;

- most crews are familiar with the method. 
The disadvantages of the saw cutting procedure include the following:

- more workers are required than in the other procedures;

- since water is used when sawing, the repair area is saturated for some time, possibly delaying the repair;

- saw overcuts weaken the repair area and must be cleaned and sealed;

- the polished, vertical repair boundary faces may lead to poor bonding;

- if more unsound concrete is later found beyond the sawed boundaries, the operation should be repeated to saw new boundaries causing extra work and further delays.

\subsection{Chip Cutting}

The boundaries in chip procedure are the same as in the saw cut procedure, except the repair boundaries are not sawed. The concrete in the center of the repair area is removed using a light jackhammer with a maximum weight of $6.8 \mathrm{~kg}$. The concrete near the repair borders is then removed using a light jackhammer with a maximum weight of $6.8 \mathrm{~kg}$ and hand tools. The work should progress from the inside of the repair toward the edges, and the chisel point should be directed toward the inside of the repair (Garbacz et al. 2013).

The chip and patch procedure may be faster because it has fewer steps; the patch boundaries are not sawed, and there are no saw overcuts to be cleaned and sealed. Once joint sawing is complete, the saw is not needed again, even if more unsound concrete is later found beyond the boundaries.

\section{Concrete Removal Techniques}

\subsection{Jackhammering}

Impacting methods with breakers are the most commonly used concrete removal systems. They generally employ the repeated striking of a concrete surface with a high energy tool to fracture and spall the concrete. Impacting methods include a wide range of devices, from hand-held chipping hammers to large machinery-mounted hydraulic breakers.

The hand-held breaker or chipping hammer is probably the best known of all concrete removal devices. Hand-held breakers are available in various sizes with different levels of energy and efficiency. The smaller hand-held breakers $(5,6 \mathrm{~kg})$ are commonly specified for use in partial removal of unsound concrete or concrete around reinforcing steel, because they do little damage to surrounding concrete. The larger hand-held breakers (11-34 kg) are used for complete removal of large volumes of concrete. Care shall be exercised when selecting the size of breakers to minimize the damage to existing concrete and its bond to embedded reinforcing steel.

Chipping hammers are typically classified by weight, even though breakers of similar weight do not necessarily generate the same impact force.

The percussive force used by pneumatic breakers to fracture concrete is primarily determined by the impact energy and the frequency at which the impacts occur. The impact energy is based on the mass of the piston, the size of the cylinder, and the inlet port diameter. Impact energy ranges from approximately $7 \mathrm{~kg}$ per blow for small tools 
to more than $82 \mathrm{~kg}$ per blow for large tools. The frequency of impact, or blows per minute, ranges from 900 blows per minute to more than 2,000 blows per minute, depending on the valve design.

Various cutting tools are available for use with hand-held pneumatic breakers. The shank end, which is inserted into the tool-retaining mechanism, is common to all. The cutting or working end can vary from a broad spade like blade to a sharp well-honed point. The vast majority of concrete removal work is done with a pointed tool, although a relatively narrow $(7.5 \mathrm{~cm}$ to $10 \mathrm{~cm})$ blade-type tool is sometimes used to remove cracked and deteriorated concrete.

Effect of the breaker concrete removal operation must be monitored to ensure minimal impact on surrounding environment. The primary issues of concern are noise, dust, and flying debris.

The first step in the removal procedure is saw cutting the repair boundaries. The deteriorated concrete in the center of the repair is then removed using a light jackhammer with a maximum weight of $6.8 \mathrm{~kg}$. The work should progress from, the inside of the repair toward the edges. When all unsound concrete in the repair area is removed and repair geometry is established the final procedure is to remove the concrete near the repair borders using a light jackhammer and/or hand tools.

Removal near the repair boundaries must be completed with hammers fitted with spade bits as gouge bits can damage sound concrete. Jackhammers and mechanical chipping tools should be operated at an angle less than 45 degrees from the vertical.

Water-wash equipment shall be used to remove sawing slurry from the repair area before it dries.

\subsection{Waterjetting}

The water jetting procedure uses a high pressure water jet to remove deteriorated concrete. A high-pressure water jet uses a small jet of water driven at high velocities commonly producing pressure of 69 to $310 \mathrm{MPa}$ and above.

High-pressure water jetting (hydrodemolition) may be used as a primary means for removal of concrete when it is desired to preserve and clean the steel reinforcement for reuse and to minimize damage to the concrete remaining in place. Hydrodemolition literally disintegrates concrete, returning it to sand and gravel-sized pieces. This process works preferentially on unsound or deteriorated concrete and leaves a rough profile. Care must be taken not to punch through thin slabs or decks if unsound concrete exists in an area to be repaired.

High-pressure water jets in the $70 \mathrm{MPa}$ range require 130 to $150 \mathrm{~L} / \mathrm{min}$. As the pressure increases from 100 to $140 \mathrm{MPa}$, the water demand will vary from 75 to $150 \mathrm{~L} / \mathrm{min}$. The equipment manufacturer should be consulted to confirm the water demand. Ultra-high-pressure equipment operating at 170 to $240 \mathrm{MPa}$ has the capability of milling concrete to depths of $3 \mathrm{~mm}$ to approximately $50 \mathrm{~mm}$.

Water jetting (hydrodemolition) should not be allowed for concrete removal if there is a possibility that unbonded post-tensioned systems are within the concrete removal zone. The only viable method of concrete removal in this situation is concrete removal using lightweight chipping hammers. 
Two trial areas, one of sound concrete and one of deteriorated concrete, are then used to determine the appropriate water jetting operating parameters. These parameters include speed, pressure, and the number of overlapping passes. Using trial and error in the test areas, the water jet must be programmed, removing sound concrete unnecessarily. In the sound area, consistent concrete removal depth of $3 / 4$ inch behind the reinforcing bar shall be obtained. After successful cutting of the above test area, with specified depth control, the operation shall be moved to the deteriorated concrete and remove all deteriorated concrete. If a result is obtained which meets the specified requirements, these parameters shall be used as a basis for the production removal. If not, the Contractor shall repeat the trial process and recalibrate the equipment or replace the equipment until a result which meets the specified requirements is obtained. Once properly calibrated, the operating parameters should not be changed while water jetting the rest of the spalls, unless the concrete changes (for example, a harder aggregate has been used in one section of the structure). If the concrete does change, the water jetting machine must be recalibrated using two new trial areas in the section with the different concrete.

All concrete within a marked for repair area should be removed to a minimum depth of $51 \mathrm{~mm}$ with neat vertical faces. Then the repair area must be tested again for soundness. Any additional unsound concrete must be removed by continued water jetting.

The debris and slurry that result from the water jettting operation must be removed using a low-pressure water stream before the slurry dries and hardens on the surface of the cavity. If this is not done, the repair area may have to be refaced. Once dried, sandblasting may or may not be able to remove the dried slurry residue. Some moisture-sensitive materials may require the repair area be completely dry before placing the material.

The advantages of water jetting include the following:

- it requires fewer workers than the other procedures;

- once an experienced operator adjusts the operating parameters, only weak concrete is removed;

- the cavity surfaces produced are vertical, rough, and irregular, and enhance bonding;

- no hauling is required.

The disadvantages of water jetting include the following:

- the finished surfaces are saturated. Placement must be delayed until the area dries unless the repair material is not moisture-sensitive;

- the fine slurry laitance remaining after the procedure requires careful attention during cleaning;

- a protective shield must be built around the repair area traffic if the patch is next to occupied areas;

- it can be difficult to control the depth of removal;

- equipment rental is expensive;

- it can be difficult to obtain a good production rate; performance of water jetting equipment has been variable;

- the waste water and debris must be handled in an environmentally acceptable manner as prescribed by local regulations. 
Although hydrodemolition will not physically damage steel tendons, it is not considered to be a viable concrete removal technique if there is a possibility of the high-pressure water coming into contact with tendons, anchorages, or both.

\section{Concrete Surface Roughness}

Interface roughness depends to a large extent on the method of substrate surface preparation. Mechanical methods of concrete removal normally leave the substrate surface much rougher than blast methods (Perez et al. 2009). The magnitude of surface roughness for concrete repairs is commonly reported in terms of surface profile amplitude.

Unacceptably rough of flat substrate profiles after concrete removal may be reduced through additional work using properly selected surface preparation technique (Courard et al. 2012). The decisions about surface preparation and its roughness in particular, cannot be made without knowing the properties and application requirements of the selected repair/overlay material (Garbacz et al. 2005).

In the general case of repairs performed with ordinary concrete, it has been shown that in the absence of substrate-induced damage, tensile bond strength increases with the substrate coarseness (Bissonnette et al. 2004). As a general rule, a concrete removal method generating the roughest profile and a sound surface shall be promoted (ICRI 310).

\section{Conclusion}

Proper attention to surface preparation is essential for a durable repair. Regardless of the cost, complexity and quality of the repair material and application method selected, the care with which concrete is removed and concrete reinforcement surfaces are prepared will often determine whether a repair project will be successful. The methods used to remove the deteriorated or contaminated concrete and prepare the concrete and reinforcement to receive the repair material shall not weaken the surrounding sound concrete and reinforcement.

Acknowledgment. The authors are grateful to the ACI Concrete Research Council, which provided financial support to this study as part of an international research project entitled "Development of Specifications and Performance Criteria for Surface Preparation Based on Issues Related to Bond Strength". Support was also provided by the Government of Poland (MNiSW), Wallonia-Brussels International (Belgium), and the Government of Quebec (Canada) through bilateral scientific cooperation programs.

\section{References}

Bissonnette, B., Courard, L.: Pull off test for the evaluation of the superficial cohesion of concrete substrates in repair works: analysis of the test parameters. Mater. Struct. 37, 342-350 (2004). (in French)

Bissonnette, B., Courard, L., Vaysburd, A., Bélair, N.: Concrete removal techniques: influence on residual cracking and bond strength. Concr. Int. 28(12), 49-55 (2006) 
Bissonnette, B., Courard, L., Garbacz, A., Vaysburd, A. von Fay, K.F.: Concrete repair bond: evaluation and factors of influence. In: 5th International Conference on Concrete Repair, Queen's University, Belfast, pp. 51-57, 1-3 September 2014

Courard, L., Michel, F., Schwall, D., Van der Wielen, A., Garbacz, A., Piotrowski, T., Perez, F., Bissonnette, B.: Surfology: concrete substrate evaluation prior to repair. In: Mammoli, A., Brebbia, C.A. (eds.) Materials Characterization: Computational Methods and Experiments IV, pp. 407-416. Wessex Institute of Technology Press, The New Forest (2009)

Courard, L., Bissonnette, B., Trevino, M.: Condition evaluation of the existing structure prior to overlay. In: Bonded Cement-Based Material Overlays for the Repair, the Lining or the Strengthening of Slabs or Pavements, Report of RILEM TC 193-RLS, pp. 17-50 (2011)

Courard, L., Bissonnette, B., Vaysburd, A., Belair, N., Lebeau, F.: Comparison of destructive methods to appraise the mechanical integrity of a concrete surface. Concr. Repair Bull. 25(4), 22-30 (2012)

Courard, L., Garbacz, A., Piotrowski, T., Sustercic, J.: Surface properties of concrete and criteria for adhesion of repair systems. In: KSPC 2013, Pristina, Kosovo, pp. 69-82, 29-30 May 2013

Courard, L., Bissonnette, B., Garbacz, A.: Concrete surface engineering. In: Modern Concrete Technology, vol. 18, CRC Press (2015). 272 pages. ISBN 13: 978-1498704885

Garbacz, A., Courard, L., Gorka, M.: Effect of concrete surface treatment on adhesion in repair systems. Mag. Concr. Res. 57, 49-60 (2005)

Garbacz, A., Courard, L., Bissonnette, B.: A surface engineering approach applicable to concrete repair engineering. Bull. Pol. Acad. Sci. (Tech. Sci.) 61(1), 73-84 (2013)

ICRI Guideline No. 310.2R-2013: Selecting and Specifying Concrete Surface Preparation for Sealers, Coatings, Polymer Overlays, and Concrete Repair. International Concrete Repair Institute, St. Paul, MN, USA (2013). www.icri.org

Perez, F., Bissonnette, B., Courard, L.: Combination of mechanical and optical profilometry techniques for concrete surface roughness characterization. Mag. Concr. Res. 61(6), 389-400 (2009) 